\title{
Análise de Trajetórias de Professores que Ensinam Probabilidade e Estatística com Auxílio do Software Iramuteq
}

\section{Analysis of Trajectories of Teachers, Teaching Probability and Statistics, With the Aid of the Iramuteq Software}

\author{
Geovane Carlos Barbosa*a; Sidney Silva Santos ${ }^{\mathrm{a}}$; Douglas da Silva Tinti ${ }^{\mathrm{b}}$; Celi Espasandin Lopes ${ }^{\mathrm{a}}$ \\ ${ }^{a}$ Universidade Cruzeiro do Sul, Programa de Pós Graduação Stricto Sensu em Ensino de Ciências e Matemática, SP, Brasil. \\ bUniversidade Federal de Ouro Preto, Departamento de Educação Matemática, MG, Brasil \\ *E-mail: geovane.barbosa@ifes.edu.br
}

\begin{abstract}
Resumo
Compreende-se que, para que o ensino da estatística e da probabilidade cumpra sua função de instrumento modificador, a formação continuada assume um papel essencial, sobretudo quando são propostos espaços formativos que superem a lógica da racionalidade técnica. Nesse direcionamento, o presente artigo é fruto de uma pesquisa qualitativa, na perspectiva (auto)biográfica, que tem por objetivo analisar narrativas (auto)biográficas de professores que ensinam probabilidade e estatística na educação básica, tomando como suporte o software IRAMUTEQ. As narrativas que compõem o corpus de análise foram produzidas durante o primeiro módulo de um curso de formação continuada no formato $\mathrm{EaD}$, gratuito, que focaliza diferentes práticas pedagógicas para o ensino da estatística. Participaram dez docentes que ensinam estatística nos anos finais do ensino fundamental e no ensino médio. Como estratégia de análise tomaram-se como base estatísticas textuais clássicas, a nuvem de palavras e a análise de similitude. As análises lexicográficas do corpus textual das narrativas evidenciaram possíveis categorias que emergiram diretamente dos dados, das quais se elegeram "Formação", "Atuação profissional" e "Anseios e expectativas" como eixos de análise. Os resultados deste estudo possibilitam enfatizar que as narrativas, quando utilizadas em processos de formação continuada de professores que ensinam probabilidade e estatística, podem auxiliar o docente na (re)construção da identidade do educador estatístico. Além disso, permitiram refletir sobre a importância da confrontação do conhecimento estatístico com os contextos sociais, para diferenciar as práticas educativas em matemática e estatística.
\end{abstract}

Palavras-chave: IRAMUTEQ. Formação Professores. Atuação Profissional. Narrativas. Pesquisas (Auto)Biográficas.

\begin{abstract}
It is believed that, for the teaching of statistics and probability to fulfill its role as a modifying instrument, continuing education plays an essential part, especially when formative spaces that surpass the logic of technical rationality are proposed. In this direction, the present article is the result of a qualitative research project, from an (auto)biographical perspective, which aims to analyze (auto)biographical narratives of teachers who teach probability and statistics in elementary education, using the IRAMUTEQ software as a support. The narratives that make up the corpus of analysis were produced during the first module of a free distance learning training course (EaD), focused on different pedagogical practices for teaching statistics. This continuing education course was attended by 10 teachers who teach statistics in the final years of elementary school and in high school. As an analysis strategy, classical textual statistics, word cloud and similarity analysis were used. The lexicographic analyses of the textual corpus of the narratives showed possible categories that emerged directly from the data, from which we chose "Training", "Professional performance" and "Wishes and expectations" as axes of analysis. Research results enabled us to emphasize that, when used in continuous education processes for teachers who teach probability and statistics, narratives can assist the teacher in the process of (re)building their identity as statistical educators. In addition, they allowed us to reflect on the importance of confronting statistical knowledge with social contexts, making it possible to differentiate educational practices in mathematics and statistics.
\end{abstract}

Keywords: IRAMUTEQ. Teacher Education. Professional Performance; Narratives, (Auto) Biographical Research.

\section{Introdução}

No cenário nacional temos percebido que a formação inicial do professor de Matemática tem oportunizado pouco aprofundamento teórico e metodológico acerca dos processos de ensino e de aprendizagem de conceitos envolvendo probabilidade e estatística. Além disso, diferentes autores (Cavalcanti \& Ferreira, 2013; Moreira \& David, 2005; Silva, 2011) sinalizam a desarticulação existente entre disciplinas específicas e pedagógicas em muitos cursos de licenciatura em Matemática no País. Em relação à disciplina de Estatística isso também ocorre, conforme indica Lopes (2013), quando aponta para a necessidade de uma formação estatística que habilite os futuros professores a elaborar atividades que promovam uma aprendizagem estatística para além do uso de técnicas e se pautem em problematizações vinculadas a contextos reais.

Ocorre que a formação estatística do futuro professor se desconecta da prática docente a ser exercida na escola. Com efeito, Moreira \& David (2005) ponderam que há uma dicotomia entre formação e prática que persiste nos cursos de formação de professores. Essa desarmonia é acentuada após a inserção profissional no ambiente escolar, conforme indicam diversos estudos (Costa, 2012; Lemos, 2011; Lopes, 2003; Silva, 2011; Viali, 2008) que apresentam - e refletem sobre elas - as dificuldades enfrentadas pelos professores de Matemática, ao propor situações de aprendizagem envolvendo 
conceitos de probabilidade e estatística, conectadas com a realidade dos alunos na educação básica.

Nesse cenário, para que o ensino da estatística e probabilidade venha a ser, de fato, instrumento modificador, a formação continuada assume um papel essencial, sobretudo quando são propostos espaços formativos que superem a lógica da racionalidade técnica (Contreras, 2002). Portanto, propor escritas narrativas (auto)biográficas nesses espaços formativos pode auxiliar os docentes a identificar suas fragilidades e potencialidades e a compreender que o ensino de probabilidade e estatística não se limita a procedimentos de fórmulas estatísticas (Lopes, 2013).

Além disso, é preciso proporcionar condições para que os docentes que atuam na Educação Básica vivenciem e reflitam sobre ações pedagógicas nas quais os alunos sejam protagonistas em processos de investigação e ação, para que os docentes possam decidir sobre a inclusão de tais procedimentos em seu repertório de ação profissional.

Tendo como base essas ponderações, estruturamos e ofertamos um curso formativo de extensão, na modalidade a distância, para promover um espaço pautado em situações de formação que ajudem os docentes a ampliar suas competências, explorar situações práticas, didáticas e metodológicas presentes no contexto dos estudantes e elaborar atividades desafiadoras e instigantes, considerando sua relevância para a atribuição de significados à Educação Estatística.

Além disso, o curso propôs a elaboração de narrativas (auto)biográficas, uma delas relatando a trajetória profissional dos participantes, que será tomada como objeto de investigação no presente artigo. Para analisar tais narrativas recorreremos ao software IRAMUTEQ ${ }^{1}$, que tem como características principais o rigor estatístico, a análise de grande volume de dados, a objetividade, diferentes possibilidades de análises, a interface simples e gratuita. Seu ferramental permite ao pesquisador analisar estatísticas sobre corpus textuais, com o intuito de comparar e relacionar variáveis específicas presentes no texto, ampliando sua visão para níveis de categorização e tomada de decisão (Camargo \& Justo, 2013).

Por conseguinte, o presente artigo tem por objetivo analisar narrativas (auto)biográficas de professores que ensinam probabilidade e estatística na educação básica, tomando como suporte o software IRAMUTEQ.

Nosso relato se inicia com algumas reflexões sobre a utilização de espaços virtuais de aprendizagem na formação continuada de professores de matemática que ensinam probabilidade e estatística na educação básica.

\section{Espaços Virtuais de Aprendizagem e a Formação Continuada de Professores de Matemática que Ensinam Estatística}

Atualmente os meios de ensino estão mudando e, a cada dia, aumenta a demanda de pessoas em busca de formação ou especialização. Mas nem sempre o acesso a esses meios de formação é fácil, pois a localização das instituições em que os cursos presenciais são ofertados pode causar, para algumas pessoas, dificuldades de acesso, pois alguns cursos não são oferecidos na sua cidade natal, ou ainda, elas não conseguem ir até o local onde acontecem os cursos presenciais.

Portanto, muitas vezes, os cursos na modalidade a distância podem ser uma alternativa para esse público, sem perder de vista a qualidade do ensino. Autores como Borba et al. (2014, p.17) corroboram esse argumento e afirmam que, ainda nos dias atuais:

a Educação a Distância $(\mathrm{EaD})$ parece ser sinônimo de algo pernicioso, que deve ser banido para que a qualidade do ensino não seja afetada. Para outros, porém, pode ser a salvação ou até mesmo a forma como as vagas públicas das universidades serão, enfim, democratizadas.

Entendemos a EaD como uma forma para que todas as pessoas, do mundo todo, independentemente de etnia ou gênero, tenham acesso à Educação de qualidade, em formação inicial ou continuada. Acreditamos, ainda, em uma EaD que possibilite e valorize a interação, o diálogo e a colaboração nos espaços de aprendizagem como fatores que condicionam a aprendizagem, uma vez que acreditamos que a qualidade da EaD está diretamente relacionada a eles.

Para tanto, nesses espaços de aprendizagem busca-se viabilizar a comunicação entre os participantes por meio de recursos tecnológicos, denominados por Borba e Penteado (2016) como mídias. Para esses autores, as mídias contemplam recursos como: chat, e-mail, áudio, vídeo, web conferência, que viabilizam a produção de conhecimento. A comunicação ocorre pela escrita, por meio de chat ou e-mail, ou por áudio e vídeo, pela web conferência. Há, ainda, a interação síncrona e assíncrona, indissociáveis em $\mathrm{EaD}$, desde que exista colaboração entre os participantes, e a qualidade da EaD está diretamente relacionada a ela, acrescida da interação e do diálogo (Borba et al., 2014).

Os recursos utilizados para comunicação assíncrona, por um lado, são as listas de discussões, os portfolios, os fóruns e os e-mails, que possibilitam que os participantes expressem suas ideias, dúvidas, tensões e compartilhem as atividades realizadas no espaço de aprendizagem, em seu tempo. Por outro lado, as interações síncronas, como chat ou web conferências permitem ao participante compartilhar e interagir com suas ideias em tempo real, mesmo a distância.

Desse ponto de vista, entendemos que espaços de aprendizagem que promovam dinâmicas nas quais os participantes vivenciem ações em contextos diversos do mundo real são fundamentais para que, por exemplo, professores em formação possam colocar em prática conhecimentos construídos ao longo do curso. Nesse contexto, é possível

$1 \mathrm{O}$ IRaMuTeQ é um software livre desenvolvido na linguagem python e que utiliza o software R para propor um conjunto de estatísticas e materiais para análise multidimensional de textos e questionários. 
a proposição de atividades que problematizem situações cotidianas, bem como a elaboração e a implementação de propostas que levem em consideração o ciclo investigativo e estimulem a reflexão (Lopes, 2003; Santana, 2011; Silva \& Guimarães, 2013; Wild \& Pfannkuch, 1999). Elas se apresentam como recursos potenciais para a formação de professores.

\section{Metodologia}

A pesquisa, intitulada "Práticas pedagógicas para o ensino da probabilidade e estatística", foi realizada durante um curso de extensão, na modalidade a distância, com foco na formação continuada para professores de matemática que ensinam probabilidade e estatística. O curso foi ofertado pelo Centro de Estudos e Pesquisas em Educação Matemática e Estatística (CEPEME), em parceria com a Universidade Cruzeiro do Sul e com a regional São Paulo da Sociedade Brasileira de Educação Matemática (SBEM/SP).

O objetivo neste estudo é analisar a trajetória profissional narrada por professores que ensinam estatística na educação básica e, para alcançá-lo, elegemos a abordagem qualitativa (Creswell \& Clark, 2013; Minayo, 2010) e a perspectiva (auto)biográfica (Nacarato \& Passeggi, 2014).

A opção pela produção de dados por meio das narrativas (auto)biográficas deve-se ao fato de elas serem "suscetíveis de propiciar à pessoa que narra um processo de reinvenção de si, na direção da autonomia e de empoderamento (formação)" (Passeggi, 2020, p. 11).

As narrativas que compõem o corpus de análises foram produzidas no primeiro módulo de um curso gratuito de formação continuada no formato $\mathrm{EaD}$ que utiliza diferentes práticas pedagógicas para o ensino da estatística. Essas produções envolveram as trajetórias profissionais de seus autores, e serão analisadas no presente artigo. Com a participação de dez docentes que ensinam estatística nos anos finais do ensino fundamental e no ensino médio, esse espaço de aprendizagem foi organizado, considerando que o curso pode proporcionar aos professores participantes uma formação que tem como base seu contexto de ação profissional.

O contexto formativo foi desenvolvido com o auxílio da plataforma Blackboard e estruturado em módulos, com vistas ao desenvolvimento da educação estatística nas escolas de educação básica. Cabe ressaltar que os dados foram coletados com consentimento dos participantes, os quais, para manter seu anonimato, serão denominados por $\mathrm{P}_{1}, \mathrm{P}_{2}, \ldots$, $\mathrm{P}_{10}$, na transcrição dos recortes das dez narrativas que serão apresentadas ao longo do texto. Para auxiliar no processo de tratamento e análise dos dados, contamos com o auxílio do software IRAMUTEQ, dado que ele permite uma gama de técnicas para materiais textuais.

Para análise das narrativas selecionamos o recurso da nuvem de palavras - visualização estrutural das frequências absolutas das palavras - e o método da similitude, que oferece ligações das palavras presentes no corpo lexical por meio de grafos. A escolha dessas técnicas organiza o vocabulário em uma forma mais clara, rápida e orientada (Camargo \& Justo, 2013; Ratinaud, 2009) e pode possibilitar ao pesquisador avanços nas análises qualitativas e quantitativas, com vistas a minimizar a subjetividade.

Com o apoio desses recursos foi possível evidenciar a matemática como eixo central e estabelecer algumas relações, que serão assumidas como categorias de análises, a saber: relação professor e aluno, atuação profissional e formação inicial e continuada.

Diante do exposto, apresentamos os resultados das análises do corpus textual das narrativas produzidas pelos professores de matemática que ensinam estatística nos anos finais e iniciais da Educação Básica por meio do software IRAMUTEQ e R. ${ }^{1}$

\section{Análise dos Dados}

Para iniciarmos a análise do corpus "Trajetórias profissionais de professores de matemática que ensinam probabilidade e estatística", procedente das narrativas escritas de dez professores de matemática da educação básica, recorremos à análise textual clássica. Por meio dela, foram observadas 7094 ocorrências de palavras, o que corresponde ao número total de palavras, sendo 1582 formas distintas presentes no corpus; 930 hápax - número de palavras que aparecem apenas uma vez em todos o corpus -; e uma média de 709.40 palavras por ocorrências em cada texto.

Além disso, para complementar os resultados apresentados pela análise textual clássica, propusemos uma representação gráfica, construída a partir do software $R$, com o uso do pacote ggplot2. A construção desse gráfico tomou como base as palavras com frequências absolutas com um mínimo de 20 ocorrências.

Recorremos a ele para proporcionar uma visão mais ampla de possíveis grupos ou categorias que podem emergir das narrativas analisadas. Desse modo, ao analisar o gráfico na Figura 1, é possível identificar três grupos, de acordo com estas frequências:

- Um grupo composto pelas palavras: curso, matemática e professor.

- Outro grupo formado pelas palavras: aula, aluno, escola, trabalhar e ano.

- Grupo constituído pelas palavras: começar, mesmo, ensino, estudar e passar.

${ }^{1} \mathrm{O}$ software $\mathrm{R}$ foi utilizado conjuntamente com o pacote ggplot2. 
Figura 1 - Palavras com frequência absoluta de pelo menos 20 contagens

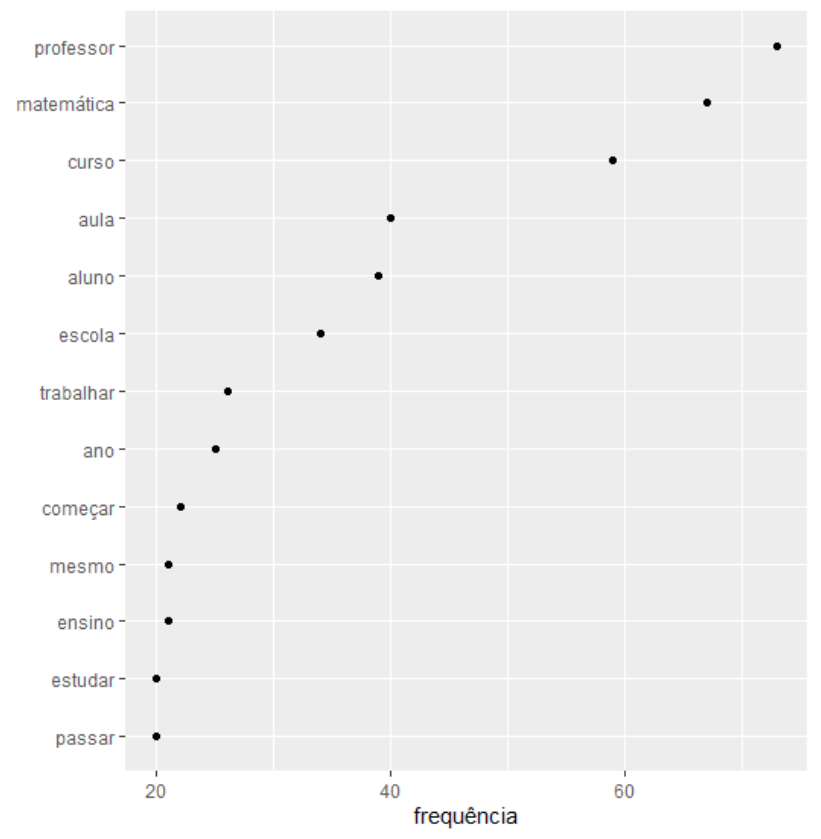

Fonte: Os autores.

Assim, podemos concluir que a análise textual clássica, alinhada com a representação gráfica, pode auxiliar os pesquisadores na organização dos dados, bem como na identificação de categorias de forma menos subjetiva. Após a análise textual clássica, recorremos a outros dois tipos de análise apresentadas pelo software IRAMUTEQ: o método da nuvem de palavras e a análise de similitude.

\subsection{Análise de narrativas (auto)biográficas por meio da nuvem de palavras}

A nuvem de palavras é um recurso que promove o agrupamento e a organização das palavras de acordo com as suas frequências observadas no corpus textual, já evidenciadas na análise textual clássica. De certa forma, essa visualização possibilitou uma rápida identificação das categorias e o apontamento de possíveis palavras-chave, que serão úteis nas análises textuais ao longo de todo este artigo. A Figura 2 apresenta a nuvem de palavras com todas as frequências registradas nas análises.

Por meio desse método, foi possível verificar que estas palavras, com suas respectivas frequências nos parênteses: "professor" (n=73), "matemática" ( $n=67)$, “curso" $(n=59)$, "aula" (n=40), "aluno" (n=39), “escola" $n=(34)$, "trabalhar" $(n=26)$, “ano" $(n=25)$, “começar" $n=(22)$, “ensino" $(n=21)$, “mesmo" (n=21), "estudar" (n=20) e "passar" $(n=20)$, foram as que registraram as maiores frequências.
Figura 2 - Nuvem de palavras contidas nas narrativas das trajetórias profissionais de professores de matemática que ensinam estatística na educação básica

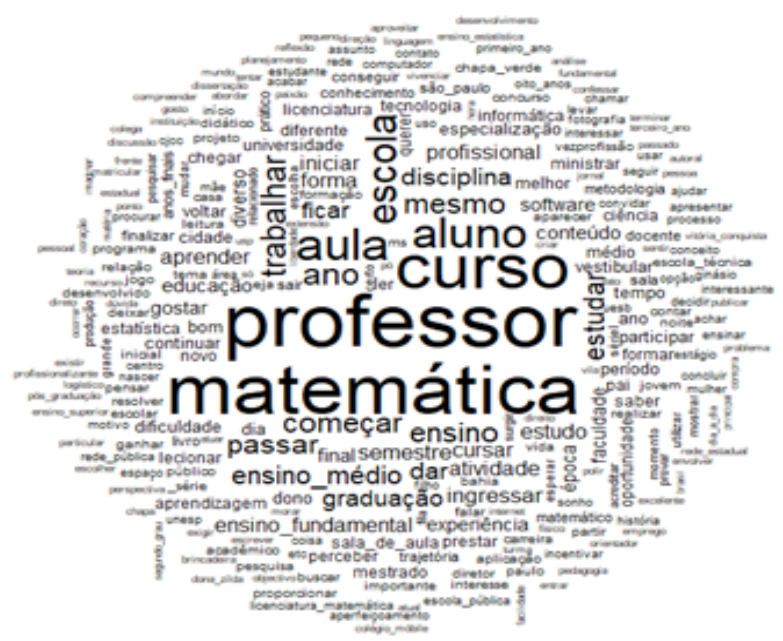

Fonte: Os autores.

No que diz respeito a esse método, é possível visualizar que a palavra "professor" e "matemática" são os dois grandes eixos centrais deste corpus textual. Notemos que a ideia central, "professor matemática", evidencia sua identidade profissional, ou seja, como professor de matemática. A palavra "professor" é tomada em muitas narrativas com forte relação com as lembranças desses profissionais ao longo de suas trajetórias profissionais. Desse modo, o aprofundamento a palavra professor, presente nas narrativas, mostra diferentes visões do papel do professor, descritas pelos alunos em suas trajetórias. A palavra "matemática" é a segunda com a maior frequência registrada pela nuvem de palavras, atrelada a diferentes contextos e situações que ampliam a sua importância na escrita das trajetórias analisadas.

Essa visualização no formato nuvem permite entender o que descrevem os docentes, suas lembranças e experiências que tiveram ao longo da vida. Reiteramos que a Figura 2 apresenta a expressão "professor de matemática" como elemento central. Ao refletirmos sobre esse fato, ficamos surpresos, pois aqui abordamos um curso de formação continuada em práticas pedagógicas para o ensino da estatística. No entanto, é latente a constituição da identidade de educador estatístico concomitante com a identidade do professor de matemática (Costa \& Pamplona, 2011; Lopes, 2020; Paiva, 2001).

A seguir, serão apresentados as estruturas categóricas e os núcleos centrais de análise, presentes nas narrativas dos professores, a partir da análise de similitude e recorrendo a recortes das narrativas, dado que a fala dos participantes amplia as análises de singularidade, as formas e a constituição desses professores, para permitir a (re)construção da identidade profissional docente em diferentes tempos e espaços (Nacarato \& Passeggi, 2013). 


\subsection{Análise de narrativas (auto)biográficas por meio da análise de similitude}

O uso da análise de similitude, do ponto de vista da análise dos dados, proporciona uma melhoria de reconhecimento de padrões e recorrências em grandes volumes textuais, como é o caso do presente trabalho. Sua utilização otimiza o tempo de organização e análise dos dados, apresenta conexidade das palavras com os grandes núcleos centrais e, principalmente, diminui a subjetividade nas pesquisas (auto)biográficas.

Assim, como evidenciado na análise estatística clássica e no método da nuvem de palavras, a análise de similitude das narrativas produzidas considerou como palavras centrais (núcleo): "matemática" e "professor" e cinco subnúcleos: aluno, aula, trabalhar, curso e ano.

A Figura 3 apresenta dois núcleos centrais: um referente ao professor e outro à matemática, o que, de certa forma, está coerente com as frequências observadas dessas palavras produzidas pelas estatísticas textuais clássicas e pela nuvem de palavras. É importante ressaltar que essa técnica de análise de similitude permite essa visualização, por ancorar-se na teoria dos grafos, o que favorece essa conexidade entre as palavras, de forma a ter um olhar macro, para identificar estruturas de representação (Marchand \& Ratinaud, 2012, referidos por Moimaz et al., 2016, p. 574).

Portanto, é possível eleger categorias que emergem da conexidade entre as palavras e dos grupos. Em meio às várias vertentes de análises e categorização de grupos apresentados pela análise de similitude, a escolha desses grupos é influenciada pelo conhecimento teórico do pesquisador e dos seus objetivos.

Nesse sentido, a categorização deste artigo levou em consideração os grandes núcleos centrais e suas ligações. Ao analisarmos a Figura 3, observamos que a palavra central "matemática" possui conexão com diversos subeixos de categorias, como: matemática $\mathrm{x}$ professor $\mathrm{x}$ aluno, matemática $\mathrm{x}$ curso, matemática $\mathrm{x}$ aula e matemática $\mathrm{x}$ trabalhar. $\mathrm{A}$ partir dessas relações, elegemos as seguintes categorias de análise: "Formação", "Atuação profissional", e "Anseios e expectativas".

a) Análise da categoria Formação

Inicialmente vamos avaliar a conexidade presente na categoria "Formação". No centro da palavra matemática, podemos observar diversas ramificações, dentre elas a estatística, objeto do curso de práticas pedagógicas proposto aos professores. A estatística se faz presente na vida desses professores sob diferentes perspectivas.

$\mathrm{P}_{2}$ : primeiro contato com a disciplina de Probabilidade e Estatística, quando cursava o segundo semestre de Licenciatura Matemática eu comecei a ter as primeiras noções, foi apenas em um semestre, e apesar de ter dificuldade no início, eu acabei que me interessando pela disciplina, e queria pesquisar mais sobre o assunto. [ênfase adicionada] (narrativa produzida por $\mathrm{P}_{2}$ no primeiro semestre de 2020)
$\mathrm{P}_{5}$ : quero ressaltar que meu primeiro contato com a Estatística foi na minha graduação, por meio de uma disciplina chamada Probabilidade e Estatística, com mais ênfase em Probabilidade, e muitos exercícios de cálculos. [ênfase adicionada] (narrativa produzida por $\mathrm{P}_{5}$ no primeiro semestre de 2020)

$\mathrm{O}$ recorte da trajetória do docente $\mathrm{P}_{2}$ revela um contato de apenas um semestre com a disciplina, porém, apesar de ter tido dificuldade, ele se ambientou e gostou do conteúdo ministrado. Esse fato corrobora os apontamentos de Silva (2011), ou seja, os conteúdos de probabilidade e estatística apresentados, em muitos cursos de licenciatura, propiciam ao aluno apenas um contato com a disciplina de probabilidade e estatística. Esse cenário priva os licenciandos de questionar práticas e estratégias de ensino da estatística para a educação básica.

Ainda no tocante à formação inicial, a análise das trajetórias revela que esses conteúdos foram apresentados ao longo de um semestre da licenciatura em matemática, e geralmente foram oferecidos a partir da segunda metade do curso. As narrativas relatam que os conteúdos abordados na licenciatura não possibilitaram aos docentes o contato com práticas pedagógicas que, de certa forma, poderiam auxiliálos a desenvolver atividades voltadas para os processos de ensino e de aprendizagem de probabilidade e estatística.

Figura 3 - Análise de similitude das trajetórias profissionais de professores de matemática em um curso de formação continuada

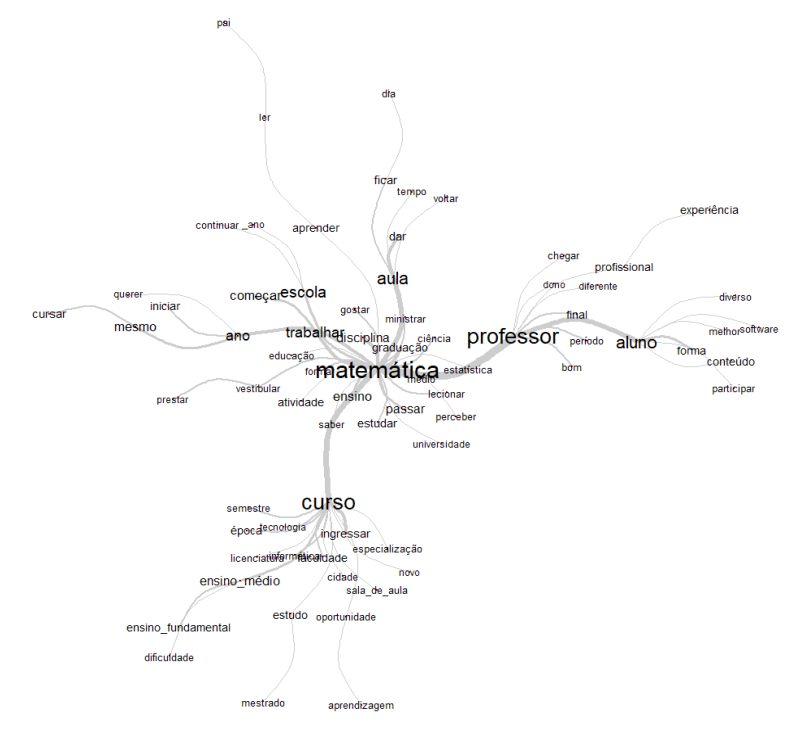

Fonte: Os autores.

A trajetória formativa descrita por $\mathrm{P}_{2}$ vai ao encontro da expectativa de Silva (2011). Esse autor sugere que o fato de a disciplina de probabilidade e estatística estar, em muitos currículos, alocada na segunda metade do curso poderia, de certa forma, ampliar o favorecimento de uma articulação vertical com as disciplinas voltadas à prática de ensino e ao estágio supervisionado, por exemplo. Porém o que se percebe 
é uma falta de articulação até mesmo no currículo prescrito nos cursos de licenciatura em matemática.

A análise do recorte da trajetória narrada por $\mathrm{P}_{5}$ possibilita ampliar as discussões realizadas anteriormente, pois, além da reduzida carga horária dedicada ao ensino de probabilidade e estatística, sinaliza a forte presença de um ensino tecnicista, acarretando a propagação dessas práticas na educação básica, dado que os professores tendem a reproduzir as experiências que tiveram em sua formação inicial (D’Ambrosio, 1993; D’Ambrosio \& Lopes, 2013).

Além disso, as práticas tecnicistas desenvolvidas pelos formadores que ministram disciplinas voltadas ao ensino de probabilidade e estatística, bem como a reduzida carga horária destinada a esse campo, colaboram para a constituição da identidade do educador matemático em detrimento da identidade do educador estatístico. Haja vista que, para que a estatística faça sentido, ela precisa partir de uma problematização que leve em consideração situações vinculadas ao cotidiano do aluno, a fim de estimular o pensamento estatístico e o pensamento probabilístico (Lopes, 2008).

b) Análise da categoria Atuação profissional

A categoria atuação profissional congrega palavras como: escola, profissional, prática, experiência e outras que aparecem nos principais eixos (Figura 3). Por meio da análise de similitude é possível analisar algumas características desse grupo e, também, evidenciar o desejo dos docentes de ampliar conhecimentos.

$\mathrm{P}_{9}$ : No período de 2010 a 2013 acumulei as funções de professor de matemática do ensino médio e diretor acadêmico da escola. Foi um período de muito crescimento profissional e pessoal. [ênfase adicionada] (narrativa produzida por $\mathrm{P}_{9}$ no primeiro semestre de 2020).

$\mathrm{P}_{5}$ : Em 2010, cursei uma pedagogia para melhorar a minha prática. [ênfase adicionada] (narrativa produzida por $\mathrm{P}_{5}$ no primeiro semestre de 2020)

$\mathrm{P}_{3}$ : Na escola técnica, tenho liberdade para seguir minhas aulas da forma que acho mais adequada. Elaboro muitos projetos de metodologias ativas que têm apresentado muitos resultados positivos. [ênfase adicionada] (narrativa produzida por $\mathrm{P}_{3}$ no primeiro semestre de 2020).

A narrativa descrita por $\mathrm{P}_{9}$, por exemplo, retrata a atuação tanto na docência quanto na gestão escolar, indicando que essa dupla função possibilita uma ampliação - tanto pessoal quanto profissional - de conhecimentos.

$\mathrm{O}$ relato do professor $\mathrm{P}_{5}$ nos ajuda a refletir sobre a importância da articulação entre os conhecimentos pedagógicos e os conhecimentos do conteúdo (Shulman, 1986). Considerando que o professor já tenha o domínio desses conteúdos (matemática), a busca por um espaço de formação que possibilite ampliar seus conhecimentos pedagógicos pode desencadear novos significados acerca dos processos de ensino e de aprendizagem da probabilidade e da estatística.

A fala do professor $\mathrm{P}_{3}$ mostra a importância de aulas baseada em projetos com base nas metodologias ativas de ensino. A abordagem por projetos dentro do contexto das metodologias ativas de aprendizagem, tanto no ensino fundamental como no médio, favorece aos alunos um ambiente desafiador, dinâmico, com posturas proativas em tarefas individuais e colaborativas, oportunizando o letramento estatístico e probabilístico. (Batanero \& Diaz, 2011; Giordano, 2016; Giordano \& Silva, 2017). Além disso, essa estratégia amplia possibilidades de o aluno escolher temas de análise dentro do seu contexto, favorecendo a manipulação de dados reais durante todo o processo de investigação estatística (Batanero, 2000; Souza et al., 2013).

Em suma, as narrativas de $\mathrm{P}_{9}, \mathrm{P}_{5}$ e $\mathrm{P}_{3}$ evidenciam que os docentes buscam em sua atuação tanto o crescimento pessoal e profissional quanto alternativas para o aperfeiçoamento de suas práticas em sala de aula.

c) Análise da categoria Anseios e expectativas

A leitura de todas as trajetórias mostra que as experiências vividas e narradas por esses docentes expõem uma dose de anseios e expectativas com relação ao desenvolvimento profissional e, principalmente, todas as barreiras vencidas durante a sua trajetória profissional.

A leitura das narrativas revela um movimento de resgate da memória que, de acordo com Passeggi (2009), atua como um instrumento de formação e de autoformação do indivíduo, promovendo análises e reflexões ao longo da escrita narrativa. Além disso, esse resgate amplia e estende a compreensão de que o espaço pedagógico se beneficia das relações existentes entre a universidade e a vida social, a teoria e a prática e entre a vida e a profissão. Revela também o cuidado na seleção das frases e dos cenários vividos pelos docentes, moldado por múltiplos caminhos que evidenciam as vozes desses professores, de suas experiências e de suas representações.

$\mathrm{P}_{9}$ : Escrever esta atividade implica em voltar o tempo, reviver emoções que marcaram minha trajetória pessoal, profissional, acadêmica... Para entender melhor as situações que interferiram em minhas escolhas considero relevante fazer um resgate do meu caminhar como pessoa, como professora, como pesquisadora. [ênfase adicionada] (narrativa produzida por $\mathrm{P}_{9}$ no primeiro semestre de 2020)

Compreender os acontecimentos que marcaram o desenvolvimento profissional de professores é compreender os caminhos por eles percorridos, os percalços encontrados e as rupturas significativas ocorridas nos cenários narrados. Além disso, essas rupturas, muitas das vezes, exigem mudanças durante a trajetória percorrida, que podem suscitar referências positivas e negativas, denominadas de incidentes críticos (Almeida, 2009; Bolívar, 2002).

Esses recortes mostram as emoções e os sentimentos proporcionados pelo desafio de ensinar matemática e estatística, numa mistura que envolve prazeres, sofrimento, expectativas, perspectivas, emoções e sonhos na busca por melhorias de suas práticas docentes. $\mathrm{O}$ ato de narrar a sua prática em sala de aula e sua trajetória profissional faz ecoar no docente sentimentos e lembranças que, muitas das vezes, 
não fazem parte do cotidiano do professor (Scarlassari \& Lopes, 2019).

Analisar as narrativas dos docentes deixa ver que eles têm uma expectativa de que os estudos propostos no curso contribuam para superar desafios enfrentados no contexto escolar e incorporar novas práticas para ensinar probabilidade e estatística na Educação Básica.

$\mathrm{P}_{1}$ : Resolvi me inscrever no curso de práticas pedagógicas em educação estatística para o ensino médio para aprender mais, atualizar, e conviver com o mundo virtual educativo. Espero vencer dificuldades. [ênfase adicionada] (narrativa produzida por P1 no primeiro semestre de 2020)

$\mathrm{P}_{3}$ : Adoro análise de dados e acredito que são ferramentas poderosas para compreendermos melhor os nossos alunos e como acontece o processo de ensino e aprendizagem. E espero continuar estudando esse assunto e quem sabe um Mestrado? [ênfase adicionada] (narrativa produzida por $\mathrm{P}_{3}$ no primeiro semestre de 2020)

$\mathrm{P}_{6}$ : Estudei e estudo muito. Acredito que, para que eu possa melhorar a minha prática em sala de aula, preciso estudar e sempre me atualizar. Não pretendo parar de estudar nunca. [ênfase adicionada] (narrativa produzida por $\mathrm{P}_{6}$ no primeiro semestre de 2020)

Conforme sinalizado pelo docente $\mathrm{P}_{3}$, a análise das narrativas dos docentes revela o anseio de darem continuidade a seus estudos.

$\mathrm{P}_{7}$ : No ano passado, iniciei uma especialização semipresencial em Educação e Tecnologias. O meu TCC versará sobre o uso de tecnologias no ensino de estatística. Acredito que esse curso de extensão acrescentará muitos elementos a ele [ênfase adicionada] (narrativa produzida por $\mathrm{P}_{7}$ no primeiro semestre de 2020)

$\mathrm{P}_{5}$ : Mesmo com quase 30 anos de trabalho docente, lecionar, me permite a renovação, o ir além buscando novas perspectivas na linguagem dos jovens. Certamente os estudos realizados não se encerram por aqui. Muitos outros passos serão dados para a construção de novos caminhos. [ênfase adicionada] (ainda este ano quero fazer a seleção do doutorado!). (narrativa produzida por $\mathrm{P}_{5}$ no primeiro semestre de 2020)

Conforme sinalizado pelo docente $\mathrm{P}_{3}$, a análise das narrativas dos docentes revela o anseio de dar continuidade a seus estudos. As análises da categoria "Anseios e expectativas" nas narrativas dos docentes evidenciam características da profissão docente, ou seja, uma atuação que requer um movimento de estudo contínuo.

Assim, esses resultados apontam que a formação continuada é um importante aliado para a junção dos saberes técnico-científicos com os saberes pedagógicos, para que o professor de matemática que ensina probabilidade e estatística possa dominar diversos cenários produzidos pelas tecnologias na disseminação da produção do conhecimento e pela democratização do acesso à escola (Farinhas, 2013).

\section{Conclusão}

O objetivo deste estudo foi analisar narrativas (auto) biográficas de professores que ensinam probabilidade e estatística na educação básica, tomando como suporte o software IRAMUTEQ. Para tanto, recorremos às narrativas produzidas por professores de matemática que ensinam probabilidade e estatística, participantes de um curso EaD, de práticas pedagógicas em educação estatística.

A análise de narrativas por meio do software IRAMUTEQ foi capaz de produzir, em poucos segundos, categorias que poderiam passar despercebidas pelo pesquisador, dificultadas pelo grande volume de dados, o que de fato, pode ocorrer quando estamos trabalhando com pesquisa (auto)biográfica. Os resultados obtidos com o software, neste estudo, possuem certa limitação e dependem da conexão entre a nossa percepção de pesquisadores e os dados empíricos da pesquisa.

Nesse sentido, as análises lexicográficas do corpus textual das narrativas evidenciaram categorias que emergiram diretamente dos dados, dentre as quais elegemos, para sustentar nossa análise, "Formação", "Atuação profissional" e "Anseios e expectativas".

A análise da categoria "Formação" permitiu identificar algumas particularidades narradas pelos docentes durante a fase de formação: a pouca importância dada à disciplina de probabilidade e estatística na licenciatura em matemática e a falta de verticalização entre os saberes técnico-científicos e os saberes pedagógicos nessa disciplina. Tais particularidades remetem à reflexão sobre os procedimentos repressivos e mecânicos que, sem dúvida, marcam os professores e indicam uma futura inserção desses exemplos contrários em salas de aula.

No tocante à categoria "Atuação profissional”, observamos um paralelismo entre a formação e o exercício profissional, ou seja, as trajetórias narradas pelos docentes são marcadas pelo estudo contínuo, com o qual buscam conhecer e implementar práticas pedagógicas diferenciadas para o ensino tanto da matemática quanto da probabilidade e estatística. Além disso, a procura por tais estratégias, ocorre em cursos de formação de continuada e também em grupos de discussão.

Ademais, o recurso da análise da narrativa revelou diferentes "Anseios e expectativas" desses professores no curso de práticas pedagógicas para o ensino da estatística, o que, para muitos, pode ser uma oportunidade de ampliar, aprender e (re)significar seus conteúdos e suas práticas em sala de aula.

Em síntese, as trajetórias narradas pelos professores do curso de práticas pedagógicas para o ensino da estatística, analisadas via software IRAMUTEQ, revelam um ambiente com diversas oportunidades de categorização, com um menor grau de subjetividade, provendo um maior rigor metodológico a pesquisas qualitativas que envolvam, por exemplo, a pesquisa (auto)biográfica.

Ademais, os resultados do presente artigo nos possibilitam enfatizar que as narrativas (auto)biográficas, quando utilizadas em processos de formação continuada de professores que ensinam probabilidade e estatística, podem auxiliar o docente no processo de (re)construção da identidade do educador estatístico. A prática profissional do professor de matemática da escola básica é uma atividade complexa, cercada de 
contingências, e que não se reduz a uma transmissão técnica e linear de um "conteúdo" previamente definido.

\section{Referências}

Almeida, L. R. (2009). O incidente crítico na formação e pesquisa em educação. Educação \& Linguagem, 12(19), 181- 200.

Batanero, C. (2000). ¿Hacia dónde va la educación estadística? Blaix, 15, 2-13

Batanero, C., \& Díaz, C. (2011). Estadística com Proyectos. Universidad Granada.

Bolívar, A. B. (2002). Profissão professor: o itinerário profissional e a construção da escola. Edusc.

Borba, M. C., Malheiros, A. P. S., \& Amaral, R. B. (2014). Educação a Distância online. São Paulo: Autêntica.

Borba, M. C., \& Penteado, M. G. (2016). Informática e Educação Matemática. São Paulo edição). Autêntica.

Camargo, B. V., \& Justo, A. M. (2013). IRAMUTEQ: um software gratuito para análise de dados textuais. Temas Psicol., 21(2), 513-518.

Contreras, J. (2002). A autonomia de professores. São Paulo: Cortez.

Costa, G. D. F. (2012). A metodologia de projetos como uma alternativa para ensinar estatística no ensino superior (Tese de Doutorado em Educação). Universidade Estadual de Campinas (UNICAMP), Campinas.

Costa, W. N. G., \& Pamplona, A. S. (2011). Entrecruzando fronteiras: a Educação Estatística na formação de professores de Matemática. Bolema, 24(40), 897-911.

Creswell, J.W., \& Clark, V. L. P. (2013). Pesquisa de métodos mistos. São Paulo: Penso.

D’Ambrosio, B. (1993). Formação de professores de matemática para o século XXI: o grande desafio. Pro-Posições, 4(1), 3440 .

D’Ambrosio, B. S., \& Lopes, C. E. (2013). Insubordinação Criativa: um convite à reinvenção do educador matemático. http://www.periodicos.rc.biblioteca.unesp.br/index.php/ bolema/article/view/8564/6584 .

Farinhas, C. (2013). Formação continuada de professores de matemática do ensino fundamental: contribuições à prática docente. In Anais do $11 .^{\circ}$ Congresso Nacional de Educação (pp. 9931-9942). Curitiba: Educere.

Giordano, C. C. (2016). O desenvolvimento do letramento estatístico por meio de projetos: um estudo com alunos do Ensino Médio (Dissertação de Mestrado). Pontifícia Universidade Católica de São Paulo, São Paulo.

Giordano, C. C., \& Silva, D. S. C. (2017). Metodologias ativas em Educação Matemática: a abordagem por meio de projetos na Educação Estatística. Revista de Produção Discente em Educação Matemática, 6(2), 78-89.

Lemos, M. P. F. (2011). O desenvolvimento profissional de professores do $1^{\circ}$ ao $5^{\circ}$ ano do ensino fundamental em um processo de formação para o ensino e a aprendizagem das medidas de tendência central (Tese de Doutorado em Educação Matemática). Pontifícia Universidade Católica de São Paulo (PUC), São Paulo.

Lopes, C. E. (2003). O conhecimento profissional dos professores e suas relações com estatística e probabilidade na educação infantil (Tese de Doutorado em Educação). Faculdade de Educação, Universidade Estadual de Campinas, Campinas
(SP).

Lopes, C. E. (20081). O ensino da estatística e da probabilidade na educação básica e a formação dos professores. Cadernos Cedes, 28(74), 57-73. doi: http://dx.doi.org/10.1590/s010132622008000100005 .

Lopes, C. E. (2013). Educação Estatística no Curso de Licenciatura em Matemática. Bolema, 27, (47), 901-915.

Lopes, C. E. (2020). A constituição de professores pesquisadores que ensinam matemática e suas identidades profissionais ativistas. Perspectivas da Educação Matemática, 12(30), 598611.

Marchand, P., \& Ratinaud, P. (2012). L'analyse de similitude appliqueé aux corpus textuels: les primaries socialistes pour l'election présidentielle française (septembre-octobre 2011). In Actes des lleme Journées Internationals d'Analyse Statistique des Données Textuelles (pp. 687699). JADT.

Minayo, M. C. S. (2010). Pesquisa Social: teoria, método e criatividade. Rio de Janeiro: Vozes.

Moimaz, S. A. S., Amaral, M. A., Miotto, A. M. M., Costa, I. C. C., \& Garbin, C. A. S. (2016). Análise qualitativa do aleitamento materno com o uso do software IRAMUTEQ. Revista Saúde Pesquisa, 9(3), 567-577.

Moreira, P. C., \& David, M. M. M. S. (2005). O conhecimento matemático do professor: formação e prática docente na escola básica. Revista Brasileira de Educação, 28, 50-61,

Moreira, P. C., \& Ferreira, A. C. (2013). O lugar da matemática na licenciatura em matemática. Bolema, 27(47), 981-1005.

Nacarato, A. M., \& Passeggi, M. C. (2013). Narrativas autobiográficas produzidas por futuras professoras: representações sobre a matemática escolar. Revista de Educação, 3(18), 287-299.

Paiva, M. A. V. (2001). Saberes profissionais de professores que ensinam Matemática: um diálogo com professores experientes. In Anais do XII SIEM.

Passeggi, M. C. (2009). Simbolizações do percurso de escrita da narrativa autobiográfica: da experiência sensível à experiência formadora. In L. M. V. Peres, E. E., \& D. L. Kurek, Essas coisas do imaginário. Diferentes abordagens sobre narrativas (auto)formadoras (pp. 148-161). Brasília: Liber livros.

Passeggi, M. C. (2020, junio). Abordagens narrativas na pesquisa educacional brasileira. Revista Paradigma (Edición Cuadragésimo Aniversario: 1980-2020), XLI, 57-79.

Ramos, M. G., Lima, V. M. R., \& Amaral-Rosa, M. P. (2018). Contribuições do software IRAMUTEQ para a análise textual discursiva. In Anais do 7. ${ }^{\circ}$ Congresso Ibero-Americano em Investigação Qualitativa (Vol. 1, pp. 505-514). CIAIQ.

Ratinaud, P. (2009). IRAMUTEQ: Interface de R pour lês analyses multidimensionnelles de textes et de questionnaires (Computer software). <www.IRAMUTEQ.org>.

Santana, M. de S. (2011). A educação estatística com base num ciclo investigativo: um estudo do desenvolvimento do letramento estatístico de estudantes de uma turma do $3^{\circ}$ ano do Ensino Médio. Dissertação (Mestrado em Educação Matemática). Universidade Federal de Ouro Preto, Ouro Preto.

Scarlassari, N. T., \& Lopes, C. E. (2019). Narrativas de professores de matemática em formação contínua. Revista Brasileira de Pesquisa (auto)biográfica, 4(10), 215-229. doi: http://dx.doi. org/10.31892/rbpab2525-426x.2019.v4.n10.p215-229. 
Shulman, L. S. (1986). Those who understand: Knowledge growth in teaching. Educational Researcher, 15(2), 4-14.

Silva, E. M. C., \& Guimaraes, G. (2013). Perspectivas para o ensino da Educação Estatística. In Anais do XI ENEM Encontro Nacional de Educação Matemática - Educação Matemática: Retrospectivas e Perspectivas.

Silva, M. A. (2011). A presença da estatística e da probabilidade no currículo prescrito de cursos de licenciatura em matemática: uma análise do possível descompasso entre as orientações curriculares para a Educação Básica e a formação inicial do professor de Matemática. Bolema, 24(40), 747-764.

Souza, A. C., Souza, L. O., \& Lopes, C. E. (2013). O ensino de estatística e probabilidade na educação básica: atividades e projetos gerados a partir de pesquisas de mestrado profissional. Vidya, 33(1), 49-65.

Viali, L. (2008). O ensino de estatística e probabilidade nos cursos de licenciatura em Matemática. In Anais do $18^{\circ}$ SINAPE Simpósio Nacional de Probabilidade e Estatística.

Wild, C., \& Pfannkuch, M. (1999). Statistical thinking in empirical enquiry. International Statistical Review, 67, 223-265. 